\title{
PATERNIDADE: A CONSTRUÇÃO DO DESEJO PATERNO ${ }^{1}$
}

\author{
$*$ \\ Luana da Silva Gonçalves \\ Centro Universitário Franciscano - UNIFRA - Brasil \\ Cristiane Bottoli \\ Centro Universitário Franciscano - UNIFRA - Brasil
}

\section{Resumo}

Esta pesquisa objetivou compreender como se constitui o desejo paterno. Para este fim foi verificado como se dá a relação de filho com quem exerceu a função de pai, identificando a atual percepção do que é ser pai e conhecendo os aspectos que influenciam diretamente o exercício da paternidade. Foi realizada uma pesquisa qualitativa, na qual participaram três homens casados, de 32, 36 e 49 anos, que vivem em união estavél e heterossexual, escolhidos pelo critério de conveniência, sendo que um ainda não é pai, outro será pai, e o terceiro já tem uma filha. A coleta de dados deu-se por meio da entrevista semiestruturada, individualmente com cada homem. Os dados foram analisados e interpretados a partir da análise de conteúdo. Compreendeu-se que a relação entre pai e filho tem grandes influências no ser pai hoje, que a percepção destes homens sobre a paternidade é que ela envolve, principalmente, o cuidado, que diz respeito ao acompanhamento e a participação direta no desenvolvimento dos filhos. Além disso, outro fator é a convivência com crianças que faz com que esses homens (re)pensem a questão do seu desejo de ser pai. Percebe-se, portanto, que todos esses processos são importantes na construção do desejo paterno.

Palavras-chave: Desejo Paterno, Família, Paternidade.

\section{Introdução}

A construção histórica da paternidade revela que, com o passar dos anos, a relação do homem com os filhos foi se modificando. O pai passou ter maior interação com eles, assumindo uma função mais ativa na educação e nos cuidados básicos com os filhos.

Diante desse panorama essa pesquisa se propõe a compreesão da constituição do desejo paterno a partir da visão de homens que querem ser, serão e são pais, verificando como se constitui a relação de filho com quem exerceu a função de pai, identificando a atual percepção que os homens têm do ser pai e conhecendo os aspectos que influenciam diretamente o exercício de ser pai para estes homens. Buscou-se também, entender quais as principais influências no processo que se constrói durante a vida do homem até à paternidade.

\footnotetext{
${ }^{1} \mathrm{O}$ projeto foi aprovado pelo Comitê de Ética para Pesquisa com Seres Humanos do Centro Universitário Franciscano sob o parecer nùmero 1.180.705 do CAAE 47811415.7.0000.5306
} 
Essa pesquisa buscou aporte teórico, principalmente em autores da Psicanálise, também buscou-se um entendimento do tema a partir de questões sociais. Essa teoria revela que o desejo paterno é analisado a partir da passagem pelo Complexo Edípico, onde o menino se vê diante de importantes e necessários conflitos e, a partir disso, vai se estruturando psiquicamente e tornando-se capaz de desejar.

Considerando que ser pai na atualidade e a partir do que a sociedade espera, implica adentrar em um mundo emocional, espaço esse, historicamente, exclusivo das mulheres, é possível que o homem venha a confrontar-se com a sua própria noção de masculinidade. O cuidar dos filhos não é apenas um jeito atual de investir nos processos educacionais deles, mas, servir às necessidades dos filhos, das mães e dos próprios pais, encorajando-os a uma paternidade mais responsável possibilitando aos homens serem mais felizes e realizados enquanto pais (BALANCHO, 2012).

Entender essas modificações presentes na constituição da paternidade é uma forma de ampliar os conhecimentos sobre o assunto, tanto em nível pessoal quanto social. Isso pode auxiliar nas práticas psicológicas que, por sua vez, podem beneficiar pais e famílias, devido à importância da presença do pai desde o parto e nos processos de desenvolvimento dos filhos. Se o desejo paterno é influenciado também pela relação estabelecida com seu próprio pai, pode-se, a partir dessas reflexões, construir relações mais saudáveis, uma vida em sociedade mais adequada e a função paterna, vir a ser mais valorizada, ocupando seu devido lugar.

Diante da importância de compreender a constituição do desejo paterno e o que o influencia, o presente trabalho se justifica. Essa temática vem conquistando mais espaços de discussão, principalmente na Psicologia. Desta forma, a pesquisa contribuirá para maior conhecimento sobre o tema, permitindo ampliar o entendimento da paternidade na atualidade a partir da visão dos próprios homens.

\section{O Complexo de Édipo}

Refletir sobre a temática do desejo paterno implica em conhecer como é construído este desejo, os aspectos que interferem na sua constituição, se isso se constrói a partir da relação estabelecida com o próprio pai, ou por ter assumido a castração simbólica através do Complexo de Édipo. Pois, no caso do menino, a função do Édipo parece muito mais claramente destinada a permitir a identificação do sujeito com seu próprio sexo, que se produz, em suma, na relação ideal, imaginária com o pai. Além disso, o que se busca também se refere à função do pai, isto é, que ele próprio aceda um dia a essa posição tão problemática 
e paradoxal de ser um pai (LACAN, 1957-58) Logo, fica clara a importância do Édipo na construção do desejo paterno, pois muitos fenômenos desse período dizem das fantasias e dos desejos que serão construídos, mais à frente, pelo sujeito.

Ainda sobre o desejo masculino do ser pai e os caminhos que são, possivelmente, percorridos pelo menino em direção ao acesso à paternidade, verifica-se que ele é, antes de tudo, desejo do inconsciente. Então, tende a se consumar e às vezes se realizar, por isso se liga prontamente a uma nova concepção do sonho, do inconsciente, do recalque e da fantasia (ROUDINESCO E PLON, 1998).

Conforme Zornig (2010), o desejo de ter um filho reatualiza fantasias da infância e do tipo de cuidado parental que o sujeito teve. Nesse sentido, Freud (1914/1916)ao falar do Complexo de Édipo e do tema do Narcisismo, dá indicações precisas sobre a interferência de ambos na constituição da subjetividade, destacando os fatores infantis que permanecem no psiquismo do adulto. Sugere ainda que o amor parental, e aí se pode localizar o desejo, seria um retorno e reprodução do narcisismo dos pais que colocaram o filho num lugar especial, "de majestade", procurando assim, através da valorização afetiva do filho, resgatar seu próprio narcisismo infantil perdido.

Ademais, o desejo de ter um filho se constrói muito antes de encontrar alguém com quem realizar isso. $\mathrm{Na}$ infância a criança brinca com bonecas e na adolescência fantasias despertam interesses nesse assunto, assim pode-se perceber algumas influências para o exercício da parentalidade (ZORNIG, 2010).

\section{O Desejo Paterno}

A paternidade implica em profundas transformações no homem. Elas iniciam com a identificação edípica ao modelo paterno apontando para a reativação da relação primordial com a mãe. Também há algumas perturbações somáticas que afetam homens durante a gestação que poderiam ser considerados reflexos dos conflitos entre o desejo de maternidade do homem e a identificação com o pai (BYDLOWSKI E LUCA, 2002).

Pensar na concepção de um filho é colocar em movimento aspectos narcísicos do pai, lembranças e fantasias de suas relações primárias, fazendo com que a criança ocupe no psiquismo parental um lugar também reparador. Assim, o acesso à paternidade implicaria em profundas transformações no homem, que se iniciariam a partir das identificações edípicas ao modelo paterno e da reativação da relação primordial com a mãe (ZORNIG, 2010). 
Conforme Aulagnier (2004) apud Violante (2007), o desejo paterno está intimamente relacionado com o amor na passagem do ser filho para ser pai. Em termos metapsicológicos, o desejo de ter filhos é uma transmissão inicialmente materna, tanto à filha quanto ao filho, mas, o acesso destes a tal desejo depende da constituição psíquica de cada um ao final de sua travessia pelo Complexo de Édipo, ao assumir (ou não, ou ainda, mais ou menos) a castração simbólica. Então, o ingresso ao desejo de ter filhos não é para quem quiser, mas para quem puder, pois, tudo isso depende da formação psíquica que cada um que compõem o casal construiu até então (AULAGNIER, 2004 apud VIOLANTE, 2007), uma construção que vai depender de toda dinâmica pessoal e psíquica inscrita desde gerações anteriores.

Ao revisitar alguns conceitos, percebe-se primeiramente, que o Complexo de Édipo nada mais é do que evento no qual o menino tem a paixão pela mãe e ciúme do pai. Porém, esse complexo de castração, assim nomeado por Freud (1924/1976) formador da sexualidade de um homem e de uma mulher, sendo que, também neste momento, se define a personalidade e a estrutura psíquica. Contudo, pensar o Édipo como um evento em que há conflitos entre o triângulo, pai, mãe e filho, como uma forma de determinar os desejos de ter ou não descendentes, é o que se pretende problematizar: se o menino tem o falo, ou seja, tem poder, por que querer ser pai? Uma criança pode ser objeto de desejo masculino? Sabemos que para as mulheres o desejo materno pode vir a ser como uma forma de saciar o desejo pela posse de um falo, e para o homem? (NASIO, 2007).

De acordo com o autor supracitado, entre a faixa etária de três (3) a quatro (4) anos, os meninos desenvolvem um foco sobre o pênis, pois, é algo vivenciado como órgão, objeto imaginário e emblema simbólico. Esta parte do corpo se torna a mais rica em sensações concretizando-se como a região erógena dominante, tornando-se referência de todos os outros prazeres corporais. O menino vivencia inicialmente isso ao olhar, por meio de comportamentos que irão repercutir nos níveis de excitação de seu órgão.

Este órgão é símbolo de orgulho, de poder absoluto e da força viril. Entretanto, se torna frágil, vulnerável, em razão da exposição aos perigos externos, passando a representar fraqueza. Com isso tem-se o representante do desejo, o "Falo", que é um pênis fantasiado, símbolo de poder e de onipotência, idealizado e de maneira controvérsia sendo símbolo de vulnerabilidade. Conforme Freud (1924/1976) os conflitos edipianos de fase fálica, a menina também acredita ter o falo, com isso as crianças desenvolvem fantasias de que todos no mundo são dotados deste poder e, todos no mundo são fortes como elas, experimentando as mesmas sensações. Assim, a angústia é sentida por ambas as partes, pelo menino em perder o falo e pela menina o sofrimento de já o ter perdido. Além disso, nessa fase acontecem também 
outras perdas, como a do seio materno, do objeto transicional, e outros eventos que permitem esse sentimento de angústia e o temor que hajam mais repetições (NASIO, 2007).

Nasio (2007), em seu livro "Édipo: o complexo no qual nenhuma criança escapa", apresenta três desejos incestuosos no menino, um desejo virtual, nunca saciado, cujo objeto é um dos pais e o objetivo seria alcançar não o prazer físico, mas, o gozo. O primeiro desejo seria o de possuir sexualmente o corpo do Outro, em particular o da mãe; o segundo, o desejo de ser possuído pelo corpo do Outro, em particular o do pai; e o terceiro, o desejo de suprimir o corpo do Outro, também o do pai, constituindo os fundadores do desejo masculino. Segundo o autor, esses três elementos são fantasias de prazer do menino. Nesse caso a fantasia é definida como uma cena imaginária do desejo incestuoso irrealizável, propiciando consolo a uma criança tomando como forma de prazer ou angústia, tendo como função substituir uma ação ideal.

Na primeira fantasia, de possuir o Outro, são adotados vários roteiros onde a criança desempenha papel ativo e se sente orgulhosa, impondo sua presença ao Outro, ou seja, no menino surge o desejo de se apoderar da mãe tendo-a para si. A outra fantasia, de ser possuído pelo Outro, é definida pelo prazer de seduzir um adulto, sendo assim a criança seduz para ser seduzida. E por fim, o desejo de suprimir o Outro, fantasia esta, que coloca o sujeito numa atitude sexual ativa, como por exemplo, o menino, na ausência do pai, brinca de chefe de família (NASIO, 2007).

Além disso, conforme Freud (1924/1976) em a "Dissolução do Complexo de Édipo", a ameaça da castração impulsiona o menino a sair do conflito edípico, por identificar-se com o pai e buscar acesso à posição masculina. Para conservar a virilidade a criança abre mão do desejo de ter a mãe (e o pai como rival), identificando-se aos atributos paternos, através da possibilidade de ser como o pai no futuro, ao invés de tentar tomar seu lugar no presente. Assim, o menino desiste da mãe e de seus objetos de desejo, com medo de ser punido, afastando-se do pai para proteger seu Falo. Instaura-se aqui a Lei do interdito do incesto, pois, o menino abandona a mãe para ir à busca de outros objetos de desejo reais, passando a desejar parceiros não integrados a família.

\section{Ser Pai Hoje}

A paternidade, com o passar dos anos, tem se transformado. Antigamente vivia-se em uma sociedade onde o papel do pai era de prover as necessidades financeiras da família e o exercício da autoridade. Os cuidados básicos, desde a higiene até o carinho com as crianças, 
eram desenvolvidos pela mãe. Atualmente, percebe-se que muitos pais participam ativamente da vida dos filhos, auxiliando nos cuidados necessários, na atenção afetiva que os filhos requerem. Tais mudanças foram influenciadas, principalmente, pela independência e a inserção das mulheres no mercado de trabalho, que as tirou de um lugar exclusivamente voltado aos cuidados domésticos e dos filhos. Por isso, ao homem foi solicitado a exercer os cuidados paternos, desenvolver tarefas que antes, apenas femininas.

O papel do pai com relação aos cuidados com os filhos foi visto por muito tempo como secundário. Balancho (2012) recorda em sua obra "Ser Pai Hoje" que o principal papel do pai na educação dos filhos era apoiar a mãe, dando-lhe suporte e segurança afetiva e econômica, de modo que ela se encontrasse em condições de se doar de forma equilibrada aos filhos. Pode-se perceber então que, aos poucos a representação de pai foi ganhando relevância, pois se vive em um momento voltado à reflexão da importância desta função, buscando reconhecê-lo pelo o que é e faz.

Em relação aos cuidados paternos, a autora supracitada destaca três tipos de presença dos pais na vida dos filhos. A interação/envolvimento, que se caracteriza pelo apoderar-se do contato direto nos cuidados e atenção e, pelo estabelecimento de diálogos que auxiliem na educação dos filhos. A acessibilidade, definida pela disponibilidade potencial do pai, não necessariamente em contato direto, mas sim, em estar física e emocionalmente disponível ao filho. A responsabilidade, que equivale à tomada de decisões, porque o pai sabe o que é preciso para o bem estar do filho e pratica atividades que envolvem esses cuidados.

Outro aspecto importante, diz respeito à interação que a mãe e o pai têm com os filhos, que pode ser diferente, visto que, cada um reage da forma que foi tratado pelas figuras parentais e de acordo com suas características pessoais. Para Balancho (2012), o pai mostra comportamentos e atitudes diferentes da mãe, pois, promove certo tipo de áreas de desenvolvimento em detrimento de outras, evidenciando formas de comunicação com filhos de configuração diversas, que pareçam relevantes no desenvolvimento das crianças.

Ademais, Benczik (2011) destaca que à figura paterna tem o papel de autoridade, mais relacionado a fornecer carinho, participando mais ativamente na vida dos filhos, através das brincadeiras e na educação e formação pessoal. O pai também divide tarefas com a mulher, sendo um o complemento do outro, na autoridade e no afeto, pois, a presença paterna na família é diferente, mas, deve ser complementar a presença materna.

Verifica-se que a ideia de paternidade se constrói associada à sociedade às características culturais de cada lugar. Para Lamy et al (2012), prende-se a ser pai a partir de diversos aspectos, que vão além do familiar, ou seja, dos múltiplos contextos onde há 
interação. A paternidade é vivida como momento importante, pois, implica em novos arranjos no ser masculino, inserindo-o de outra forma na cultura e no reconhecimento social, atravessado inicialmente pelo que lhe constituiu, o seu desejo.

Isso indica que existem diferentes formas de ser pai, visto que, um pai pode exercer todas essas presenças ou apenas uma delas, e também desenvolver outras que ainda são desconhecidas. Em razão disso, é importante discutir e refletir sobre o que este pai realmente faz como se configura a paternidade atualmente e qual a relação disto com o desejo que o impulsionou a ser pai.

\section{Método}

Esta é uma pesquisa qualitativa, que segundo Martins e Bicudo (1994) busca a compreensão particular daquilo que se estuda, não se atendo a generalizações, princípios e leis, e tendo como foco da sua atenção o específico, peculiar, individual, desejando a compreensão e não a explicação dos fenômenos estudados, a partir do tema proposto.

Integraram a pesquisa três homens, com 32 anos, casado a nove anos, com ensino superior, 36 anos, casado a cinco anos e com ensino superior e 49 anos, casado a vinte e cinco anos, com ensino tecnico, respectivamente. Os participantes vivem três momentos distintos: um deles ainda não é pai, mas deseja ser; outro está vivendo o momento da gravidez da esposa e o terceiro já é pai. Destaca-se também que, ambos estão em uma união estável com a mulher.

Para a coleta de dados, foi aplicada a entrevista semiestruturada, realizada individualmente, com cada participante, na sua própria residência. As questões que nortearam a entrevista foram: 1) A partir de que momento você decidiu ter filhos? 2) Como é a sua relação com seus filhos ou como acha que vai ser? 3) Quais os desafios que você percebe na paternidade ou no ser pai hoje? 4) Como foi a relação entre você e seu pai? Nogueira-Martins e Bógus (2004) compreendem que a entrevista semiestruturada parte de certos questionamentos básicos, apoiados em teorias e hipóteses, que interessam à pesquisa, oferecendo amplo campo de interrogativas, fruto de novas hipóteses que venham a surgir, à medida que se recebem as respostas do entrevistado. $O$ mesmo seguirá a sua linha de pensamento e trará suas experiências dentro do foco colocado pelo pesquisador. As perguntas fundamentais que integrarem a pesquisa serão resultado não somente da teoria que move o pesquisador, mas, também, de toda a informação que ele já recolheu sobre o fenômeno que interessa. 
O contato inicial com os participantes foi realizado por ligação telefônica, através da qual foi combinado o local, data e hora para a realização da entrevista. Após o consentimento dos mesmos foi garantindo o direito de sigilo ao participante. Posteriormente, cada participante foi entrevistado no seu domicílio, onde foi entregue o Termo de Consentimento Livre e Esclarecido, em duas vias, foi lido e assinado pelo participante da pesquisa. O mesmo garantiu o anonimato, atendendo aos princípios éticos de Realização de Pesquisa com Seres Humanos, previstos na Resolução No 016/2000, do Conselho Federal de Psicologia (CFP) e do Conselho Nacional de Saúde, Resolução No 466/2012.

Após, foram realizadas as entrevistas, que, mediante o consentimento dos participantes, foi gravada e posteriormente transcrita na sua íntegra, para melhor compreensão dos dados coletados. Cada entrevista durou, em média, 30 minutos. Após a conclusão deste trabalho os materiais transcritos serão guardados por cinco anos. Haverá também uma devolução aos participantes, conforme o interesse e disponibilidade dos mesmos.

Os dados coletados foram analisados e interpretados a partir da análise de conteúdo, que, conforme preconiza Bardin (2009) é uma técnica para se estudar e analisar a comunicação de maneira objetiva, sistemática e quanlitativa. Busca inferências confiáveis de dados e informações a respeito de determinado contexto partindo dos discursos escritos ou orais de seus atores. A análise de conteúdo fará parte do planejamento e desenvolvimento do trabalho de campo do estudo de caso, auxiliando no processo de descrição e compreensão do material coletado (MARTINS, 2006).

\section{Resultados e Discussões}

Para facilitar a compreensão dos dados coletados e organizar a análise, os participantes foram nomeados como Pai 1 - ainda não é pai, mas deseja ser; Pai 2 - aguarda o nascimento do primeiro filho; Pai 3 - já é pai. A partir das entrevistas realizadas e considerando que cada participante vive um momento distinto em relação à paternidade, foram definidas três categorias de análise: Relação pai e filho; Ser pais e os desafios; Desejo paterno, que serão apresentadas e analisadas a seguir.

\section{Relação Pai e Filho}

Inicialmente será apresentada uma descrição de cada entrevistado a partir da relação estabelecida com o próprio pai. Suas falas estarão sendo relacionadas com a teoria revisada. 
O Pai 1 tem com 32 anos, é casado há 9 anos com sua esposa e no momento estão planejando ter um filho. O histórico familiar desse homem é marcado pela separação de seus pais, quando tinha 7 anos. Entretanto ele destacou que sempre teve um relacionamento tranquilo com o pai, mesmo com a separação e a distância que esse tomou. Salientou que, ainda assim, conseguiram manter contato. Destacou que foi criado mesmo pela mãe, a base para toda a sua vida, influência direta na construção das ideias sobre a paternidade e o ser pai. Demonstrou orgulhar-se muito de sempre ter trabalhado, dizendo que aprendeu a trabalhar cedo com o pai.

\begin{abstract}
Olha, sempre foi boa né [referindo-se a relação com o pai], apesar de que o meu pai quando eu tinha [...] 7 anos de idade ele se separo da minha mãe né, então eu fui criado mesmo com a minha mãe, mas apesar da separação e da distância que a gente mora [...] não foi nenhum empecilho, a gente sempre manteve uma relação [...] mas se um dia eu precisar ele vai ta ali pra me ajudar (Pai 1).
\end{abstract}

Em relação ao desejo de paternidade, o Pai 1 contou que o mesmo foi "aflorado" devido ao nascimento de sua sobrinha, já que acompanhou o início da gravidez até o presente momento da vida dela.

\footnotetext{
Nossa ideia de ter uma criança já vinha, a gente já vinha estruturando né, o meu irmão teve a segunda filha dele, há cinco anos atrás e nasceu a nossa afiliada e [...] a gente acompanhou desde o início da gravidez, acompanhou o parto tudo né, e isso veio aflorando (Pai 1).
}

Percebeu-se que o papel de pai que lhe foi transmitido é de alguém que coloca valores na vida do filho, e também que esse pai que ele deseja ser tem uma forte influência da mãe dele. Porém destacou que seu pai, mesmo distante, teve um papel importante na sua vida. Nesse sentido, Dantas et al. (2004) supõe que um pai presente, além de servir de referência acerca do universo masculino, seria alguém capaz de dar ressonância de forma positiva às questões emocionais, sociais, afetivas e cognitivas dos filhos. E, Ramires (1997) completa destacando que, devido à diminuição do contato existente entre o pai e o filho, após a separação, o pai busca uma vivência de maior qualidade, justamente para compensar a sua ausência diária.

Pra mim tirá de bom nessa história [...] a única coisa que eu posso te dizer assim é a questão do caráter [...] pra minha parte de ser pai, do meu pai da minha convivência, eu acredito que meu pai sempre foi uma pessoa batalhadora, ele sempre buscou os seus ideais, trabalhou, correu pra adquirir e ter o que ele tem hoje e isso eu posso me espelhar, ser uma pessoa lutadora, ser uma pessoa batalhadora [...] eu quero que ele (o filho) tenha uma vida familiar ótima (Pai 1).

O Pai 2, é casado há 5 anos, e sua esposa está grávida do primeiro filho deles (31 semanas de gestação. Ele foi adotado com 10 anos, trazido para ajudar o casal no negócio da 
família e cuidar deles, visto que, já eram idosos. Sua relação com o pai adotivo, modelo e exemplo, sempre foi tranquila. Manifestou ter muito orgulho de ter sido criado por ele. Com o pai e a família biológica contou que tem contato à distância e avaliou esse convívio como bom. Entretanto, destacou que quem o ensinou a ser a pessoa que ele é hoje foi o pai adotivo, que lhe repassou valores significativos.

Contato com o meu pai biológico até hoje [...] não é um convívio diário, mas sempre um bom convívio, e com o meu pai de criação nem se fala né, foi um exemplo pra mim [...] foi ele quem me ensinou ser a pessoa que eu sou hoje, só tenho orgulho de ter sido criado por ele, criação excelente [...] que tu saia na rua as pessoas te respeitem, e pra ti ser respeitado tu tem que ter uma postura de boa índole né [...] então foi os valores que ele foi me ensinando desde novo (Pai 2).

Em relação às influências na criação dos filhos, percebeu-se pontos comuns associados à transmissão de valores, para os Pais 1 e 2. Além disso, o Pai 2 demonstra a vontade de ser um pai diferente, trazendo para o filho outras oportunidades que ele não teve, como por exemplo, o uso das tecnologias.

\begin{abstract}
Antes a gente tinha uma infância, a gente brincava com os amigos de colégio, de vizinhança, hoje não, hoje a criança brinca com computador né, com computador, com tablet, com internet, e isso eu acho que deixa um pouquinho pra traz a infância, os princípios da educação infantil eu quero ver se consigo limitar, não que o meu filho não vá ter acesso [...] mas, vai ter os momentos dele ter isso ai [...] porque eu fui criado assim e acredito que é a melhor maneira (Pai 2).
\end{abstract}

A transgeracionalidade resgata os componentes que perpassam a história familiar e se mantém presentes ao longo das gerações. Nesta definição, conforme Wagner e Falcke (2005), encontra-se claramente ideias de repetição, reedição e reprise de determinados processos familiares, com diferentes nuances. Percebe-se que os processos transmitidos pela família de uma geração a outra se mantem presentes na história familiar. Também se verifica que há grande relevância em transmissão de valores dentro das famílias, onde esses homens querem passar adiante aos filhos, o que receberam dos pais, dentro de um contexto atual, onde se prioriza o estudo e a carreira profissional.

Com certeza, muitos ensinamentos eu vou levar [...] caráter e honestidade [...] a educação que eles me deram [...] vai ser um exemplo pra mim trazer pro meu filho, basicamente educação [...] eu não sei como a gente vai tá trazendo, se vai ser da mesma maneira que eles colocaram pra mim ou a gente vai ter um jeito diferente vai colocar, isso o dia a dia da nossa vida vai colocar (Pai 2).

O Pai 3 esta com 49 anos, é casado há 25 anos e tem uma filha de 9 anos. Escolheu ter filhos logo após o casamento, porém devido a problemas de saúde do casal não houve sucesso, isso os conduziu a adoção de uma criança. A relação com o seu pai foi rígida, a educação também, porém ‘algumas recordações boas', como ele disse, ficaram. 
Foi bem diferente né, porque meu pai era um homem muito rígido né, não que eu não seja um pouco rígido, mas eu não chego perto do pai [...] meu pai não falava pra nós, ele só olhava [...] claro que muitas vezes exagerado né, que os antigos era assim [...] meu pai me ensinou a fazer tudo na verdade ele não nos ensinava, ele dizia, presta atenção no que tô fazendo né, porque um dia vocês vão precisar (Pai 3).

Para o Pai 3, apesar da rigidez na educação recebida, algumas coisas serão levadas para continuar criando sua filha. Para ele não aparece fortemente à questão dos valores como com outros entrevistados, mas sim, uma grande preocupação em relação a educação escolar da filha e também, questões ligadas a sua personalidade.

Na questão da educação, de dar as coisas desnecessário, eu acho que tu aprende
assim, que o demais atrapalha e o de menos também atrapalha né [...] aquela falta de
carinho e atenção tu dar pro teu filho com presentes, com coisas [...] eu acho que
aquele exemplo que eu tenho do meu pai que [...] que nos educar, nos dá atenção
quando necessária né, eu acho que isso aí influencia e ajuda bastante, as raízes são
muito importante [...] se teu pai não tiver bons exemplos o filho não vai ter bons
exemplos [...] então eu acho que a educação do pai traz muita coisa pra gente (Pai
3).

De acordo com Gabriel e Dias (2011), a experiência da paternidade depende também da relação vivida entre pai e filho, no passado, que influencia o modo como o homem compreende e assume a sua masculinidade. Para sua realização como pai, ele busca referências em seu próprio pai, encontrando, na maioria das vezes, o modelo de pai distante e pouco envolvido afetivamente, referencial de masculinidade ainda hegemônico. O filho incorpora esse modelo, construindo uma subjetividade distanciada da valorização do afeto, ao mesmo tempo em que tem na sua mãe o exemplo de cuidado. Reproduz-se, portanto, a relação pai-mãe-filho, tal como determinada socialmente e experimentada na sua vivência, evidenciando um mecanismo ideológico de reprodução do conservadorismo do esperado socialmente. Essa dinâmica relacional ficou evidente na fala dos entrevistados, porém com uma tentativa de ser diferentes em alguns aspectos, tanto naquele homem que quer ser pai, quanto naquele que está prestes a ser, e como naquele que já é pai.

\section{Ser Pai e os Desafios}

A partir das percepções supracitadas, que mostram a trajetória desses homens, com base na vivência com o próprio pai, serão apresentadas as ideias construídas por eles de paternidade, baseadas nas experiências familiares formando assim a própria concepção do que querem exercer como Pai e alguns desafios presentes neste contexto.

Diferente do que lhe foi passado, o Pai 1 deseja ser um pai afetivo em todos os sentidos. Isso, para Piccinini et al. (2004), demonstra que os pais estariam mais ativos em sua 
parentalidade, exercendo influências diretas sobre o desenvolvimento de seus filhos. Desta forma, existe uma nova consciência de que criar um filho é também função do pai. Contudo, ainda não há clareza quanto a este novo papel, e aqueles homens que assumem esta responsabilidade nem sempre recebem apoio social (BRAZELTON 1988 apud PICCININI et al., 2004).

\begin{abstract}
O meu sentimento é de amor, de paixão, de carinho, é um sentimento verdadeiro, um sentimento puro [...] de troca de afeto [...] acho que o sentimento maior do mundo é ter um filho, a gente pode chegar em casa de tardinha cansado, as vezes estressado do serviço, encontrar um filho, brincar, se desestressar [...] leva o filho na pracinha pra brincar, leva num estádio de futebol [...] enfim é um sentimento que eu quero, como eu disse estruturar minha vida profissional e social, pra mim poder a partir de ter um filho, eu poder curti o meu filho, participar ativamente da vida dele (Pai 1).
\end{abstract}

Sobre o significado da paternidade, o Pai 2 não foi claro, possívelmente pelo fato de que três anos atrás não haver o desejo de ser pai. A esse respeito, Piccinini et al. (2004), lembra que o envolvimento paterno pode variar bastante ao longo da gestação, de acordo com o desenvolvimento do bebê, bem como conforme as características de cada pai.

Se eu for bem sincero em te dizer, no começo [...] quando a gente casou, e até antes
de a gente começar a discutir, eu dizia que eu nunca queria ter filhos [...] eu sempre
fui uma pessoa que dizia assim, eu não quero ter filhos, porque eu queria ter uma
vida só minha e da minha esposa [...] essa era uma visão vou te dizer assim, até dois
três anos atrás posso te dizer bem tranquilo [...] não me enxergava eu tendo um
filho, só que com o tempo [...] e ver como é difícil as vezes um casal ser sozinho [...]
isso começou a fazer eu pensar que "Não!" vai chegar o momento que nós vamos ter
que ter um filho (Pai 2).

Já o Pai 3 descreveu como sendo um sonho de todo o ser humano. Um desejo tão grandioso que não é possível descrever em palavras. Ficou marcada a intensidade na sua fala, talvez por já ter um convívio com a filha.

A questão de ser pai é aquela coisa, acho que todo mundo tem o seu sonho de ser pai $[\ldots]$ acho que todo o ser humano que [...] que pensa [...] acho que pensa em ter um filho né, raramente a gente vê na televisão ah não quero ter filho [...] porque eu acho que todo o homem sonha em ser pai (Pai 3).

Marcando essa intensidade, emoção, ele continuou:

É pra gente [...] pra mim né [...] é uma coisa muito gratificante né [...] ser pai é uma coisa maravilhosa [...] mas pra mim é assim, é uma coisa que praticamente não tenho o que te dizer, de [...] de [...] simplesmente eu acho que é uma coisa maravilhosa, que resume tudo né (Pai 3).

Ainda, no que diz respeito à relação afetiva enunciada, ela pode ser discutida à luz de gênero. Os homens tentam viver a experiência do ser pai, rompendo estereótipos do passado e se aproximando dos aspectos afetivos dessa relação de modo que ser pai compreendido como ser provedor dá espaço para a emoção e afeto (Freitas et al.,). Então, o estabelecimento de 
laços entre os pais e o bebê favorece seu desenvolvimento afetivo e cognitivo, mas, ao mesmo tempo, propicia aos pais o sentimento de serem "pais suficientemente bons" especificamente para aquele bebê. Ressaltam ainda a dimensão simbólica do acesso à parentalidade, sugerindo que o nascimento de um filho transforma definitivamente o psiquismo de cada um dos pais.

Houzel (2004) explora os conceitos da parentalidade, a partir de três eixos, que podem ser utilizados para ilustrar o momento que cada um desses homens vive. No eixo 1 se encontra o Pai 1, que estaria organizando sua parentalidade, ou seja, exercendo o seu direito de exercício da parentalidade, podendo planejar os recursos para a consolidação do desejo de ter um filho. No eixo 2, o Pai 2, que faz o que o autor chama de experiência da parentalidade, caracterizada pelo conhecimento subjetivo consciente e inconsciente, de vir a ser pai e de preencher papeis parentais, através do desejo pela criança e do processo de transição em direção à parentalidade ou parentificação. E, no eixo 3 está o Pai 3 que vive a prática da parentalidade, designada como as tarefas cotidianas que os pais executam junto à criança, entendidas pelos cuidados não somente físicos, mas, também os psíquicos.

Com relação aos desafios de ser pai parece haver em comum nas falas dos três uma preocupação com a educação que passarão aos filhos, em relação a questão das drogas e a crise econômica do país.

Primeiro eu acho que é primordial é [...] é a educação [...] a gente tem que pensar nessa questão bem antes de educar um filho [...] essa questão do estudo eu já venho estruturando, a gente quer, desde o início ter uma reserva financeira pra poder aplicar num estudo melhor, dar uma condição pra criança poder estudar e ter uma condição de estudo, que hoje em dia é bem difícil [...] (Pai 1).

Desafios [...] que seriam o principal, a educação em casa [...] é um desafio muito grande [...]. Estudo, eu acho que vai ser um grande desafio, pra nós no futuro [...] tentar colocar desde cedo numa profissão e isso é um grande desafio que nós temos, e sem contar a questão de segurança, questão de drogas [...] enquanto ele é bebê, pequeno a gente vai tá blindando [...] o momento que ele começar a sair, que vai começar a ter coleguinhas, a ter amigos [...]. Tentar ter bastante cuidado, pra tentar direcionar com a melhor turma possível (Pai 2).

A educação principalmente né, a educação que é uma coisa hoje mais complicada porque, o [...] a [...] criminalidade tá aí, a [...] as más influências estão aí, internet, telefone, né. A gente tá dando pra ela hoje de educação, pra ela né [...] ela retribua no futuro [...] da maneira melhor possível que seja uma criança [...] educada, querida por todo mundo (Pai 3).

O Pai 1, entretanto, foi o único a falar sobre a grande preocupação em ter um bom relacionamento com o filho.

$\mathrm{Eu}$ acredito que a dificuldade maior é a gente ter um bom relacionamento com o filho, um pai e uma mãe tem a responsabilidade a partir que coloca uma criança no mundo, e [...] acredito que a dificuldade maior seja essa, de ter um bom relacionamento, de ter uma confiança entre os dois, é [...] no dia a dia, em todos os afazeres [...] a educação familiar é a educação que ele vai ter pra vida inteira, então... 
é [...] o meu pensamento é que se ele tiver uma formação boa em casa com certeza ele vai ser um profissional promissor, uma pessoa de caráter bom, uma índole saudável (Pai 1).

Entretanto, a grande preocupação dos participantes dessa pesquisa foi educação dos filhos tanto no aspecto pessoal, quanto escolar. Foram apresentados diversos fatores de preocupação: a situação em que o país se encontra; a angústia pelo futuro do filho; as ameaças externas em relação às companhias, o uso de substâncias; a profissão que irão seguir. Essas, por sua vez, são preocupações pertinentes, pois, segundo Souza e Sanguinet (2012), o desenvolvimento de um filho implica em um aumento expressivo na rede social do mesmo, passando a conviver com outros grupos, principalmente através da escola que proporciona conhecer novos costumes, compartilhar novas ideias, influenciando diretamente nas relações estabelecidas.

\section{Desejo Paterno}

Referindo-se ao desejo paterno o Pai 1, falou da vontade real de ter um filho, que surgiu a partir do nascimento da sobrinha. Isso pode indicar que o convívio com crianças influencia o desejo de ser pai. Por outro lado, questões que ele trouxe como justificativa pra pensar em não ter filho e ao mesmo tempo necessidade de se programar pra ter, pode indicar uma ideia de paternidade idealizada.

Bom, na verdade o meu sonho de ter filhos [...] 4 ou 5 anos atrás eu já sentia essa... essa vontade de ter filho, o meu irmão quando ele ganhou a segunda menina dele, foi quando que aflorou vamos dizer assim essa ideia de ter (Pai 1).

O Pai 2 também percebe o seu desejo construído através da convivência com os filhos de amigos, tendo em vista que ele, até então, não teria interesse em se tornar pai. Novamente pode-se inferir de que o contato com crianças, para estes homens, foi determinante para o surgimento do desejo de paternidade e o exercício dessa função, não deixando de lado questões edípicas que são revividas neste momento. Krob, Piccinini e Silva (2009), destacam que a satisfação dos homens com a paternidade pode ser associada a alguns fatores como, o desejo de ser pai, o planejamento da gravidez e o fato de gostar de crianças, o que faz com que tenham mais segurança para depois saber lidar com as necessidades do próprio filho.

Como os amigos da gente também tem filhos, e a gente convive [...] vai pegando amor e vai mudando o pensamento, e foi isso que mudou o meu pensamento porque se eu ficasse isolado eu teria o meu pensamento de não ter filhos, só que a gente tem vários amigos que tem filhos, e a gente brincando e vendo a alegria que traz [...] que criança só traz felicidade, não tem por que não ter um né (Pai 2). 
Já o Pai 3 trouxe parte de um pensamento onde todo o homem sonha em ser Pai, que é da natureza ter este desejo de paternidade, ressaltando também o processo de legado, onde um filho dá sequencia à família.

Então na questão quanto a querer ser pai, é um sonho de todo o ser humano acredito eu, que todo o ser humano consciente ele pensa em deixar alguém, como se diz, uma sequência da sua própria vida né, eu acredito que isso ai já é uma lei de Deus como se diz, lei natural né (Pai 3).

Pode-se depreender que o desejo de ser pai é construído através de muitas influências, na convivência com o próprio pai, na criação com a mãe, no desejo da companheira, no convívio com crianças, aspectos esses que podem se tornar dispositivos para alimentar a ideia de ter filhos. Outro aspecto a ser destacado é que, o momento que cada homem está vivendo pode influenciar no desejo de ser pai, principalmente em relação à forma como ele se organiza e se prepara para criar um filho, seja buscando uma determinada implicação no exercício da paternidade, ou ilustrando com as idealizações que aparecem nas suas falas.

Não é só financeiro [...] mas te preparar, ter um estudo [...] tem cursos a vontade pra
ser pai, ser mãe, aprende isso e aquilo e com certeza a gente faz, eu faço isso e não
tenho vergonha de dizer, porque eu to me preparando pra isso mesmo [...] tem que
estudar, tem que ter uma formação, tem que ter uma parte bem alicerceada, familiar,
primeiro o casal, e se entender muito bem (Pai 1).

Hoje tem auxílio da internet, bastante pesquisa, às vezes a gente fica um pouco apreensivo, porque a gente não sabe como se vai andar, eu acredito assim, que se eu conseguir passar a criação que tive pro meu filho [...] eu acredito que ele vai ser uma pessoa de bastante sucesso, e eu como pai também vou ter bastante sucesso (Pai 2).

Para o Pai 3 a paternidade, vivenciada no dia a dia, traz como significado a prática, o que faz com a filha e o que sente, não deixando de idealizar a partir daquilo que ele imagina como correto.

Ela gosta de ser o centro das atenções, até surgiu um comentário esses tempos que [...] ela gostava de mandar e quem não brincasse com ela, ela brigava, aí eu fui no colégio conversar com a diretora, pra ver se era verdade, a diretora disse que não [...] que ela é uma criança carinhosa, prestativa, educada [...] ela é muito humanitária também, gosta de ajudar as pessoas [...] e realmente a gente nota isso [...] Ah! Pra um pai é uma realização né, porque a gente pode [...] ta conseguindo educar da maneira que a gente acha correto (Pai 3).

Nesse contexto produzido pelas vidas partilhadas, ficam visíveis as diferenças em cada momento vivenciado. Também é perceptível que são vivências muito significativas, pois os dois pais que ainda não tem o filho nos braços, idealizam e planejam muito, e isso evidencia a fantasia que há na concepção de preparar-se para ser pai. Sobre esse aspecto, Maldonado et al. (1997) afirmam existir pais que procuram sentir o bebê na barriga da mulher, acompanham as consultas pré-natais, ajudam a compor o enxoval e organizar o quartinho do bebê. Eles podem 
mostrar maior interesse por bebês, gravidez e parto lendo livros sobre o assunto e buscando todas as informações disponíveis. Porém, pelo momento vivenciado, o Pai 3 tem percepções diferentes, é algo concreto, no real, sendo as preocupações e idealizações distintas por já ter a prática de paternidade.

Similarmente, Ramires (1997), em pesquisa realizada sobre o exercício da paternidade ressalta que muitos pais manifestam um desejo de ter uma relação próxima, de amizade e confiança com os filhos percebendo que, à medida que conquistarem a amizade e confiança dos mesmos, poderão auxiliá-los em seu desenvolvimento, oferecendo-se como um parceiro com quem eles poderão contar ao enfrentar as dificuldades e conflitos, inerentes a todo o processo de crescimento e amadurecimento. Nas entrevistas, são encontradas semelhanças com o proposto pelos autores, já que há um desejo de implicação e participação desses pais no desenvolvimento dos filhos, uma preocupação que antecede a gravidez, percebida na vontade de ser pai, e o investimento feito por cada um a sua maneira, partindo de uma realidade interna e externa, tornando-os mais ativos neste processo.

Em sua fase adulta, aquele menino que agora é pai, desenvolverá e construirá aquilo que foi passado, repetindo a experiência que lhe foi apresentada, construindo ou reconstruindo a figura paterna que ele teve. Por essa razão, a vivência no Édipo influenciará na personalidade formada e na função paterna exercida por esse homem, e a resolução edípica permitirá a triangulação relacional, possibilitando-lhe, no futuro, aceder à paternidade e abrir espaço para o bebê funcionando como ligação entre ele e o mundo.

\section{Considerações Finais}

A partir do presente estudo, verificou-se que a relação entre pai e filho tem grandes influências no ser pai hoje, pois, o homem pode escolher entre reproduzir ou ser diferente daquilo que viveu na condição de filho. Também foi possível observar que a percepção destes homens sobre a paternidade é de uma tarefa de cuidado, não apenas de prover as necessidades, mas de estar ativo na vida do filho, cuidados esses, básicos, que dizem respeito ao acompanhamento e a participação direta.

Percebe-se então que o desejo paterno é construído através da relação que o homem teve com seu próprio pai, querendo ser um pai diferente, ou seja, possibilitando que o filho tenha mais oportunidades e recursos que este homem não pôde ter. A convivência com crianças também se mostrou determinante na vontade de ser pai, sendo um dos fatores influentes para a construção do desejo paterno. 
Através das entrevistas pode-se, claramente, responder aos objetivos da pesquisa, que se propôs a analisar a construção do desejo paterno e suas influências, para poder abrir espaço para discutir a paternidade com os próprios homens que a vivenciam.

Tendo em vista os diferentes momentos da vida dos participantes dessa pesquisa, foi contemplada, mais especificamente a percepção da transição e dos sentimentos com relação à ideia de paternidade, onde ficaram claros os processos de idealização e o que se constituiu até então enquanto conceito de ser pai. O filho passa a ser o resultado de tudo o que se construiu durante a trajetória vivida, ou seja, através dele se almeja alcançar todos os objetivos de alicerçar uma vida, para só então começar a planejar o processo de preparação para a paternidade até a realização do desejo, assim este homem poderá se debruçar na criação de seu filho.

A pesquisa possibilitou analisar também a grande expectativa que há em comum para estes homens tanto para aquele que vai tornar-se pai quanto para o sucesso na paternidade. Isso foi ressaltado em vários momentos das entrevistas realizadas, mas como distinção entre eles. Observou-se que aqueles que ainda não tem o filho nos braços idealiza muito mais a ideia de paternidade, e quem já tem a prática percebe-se o quanto é concretizado e real, sem deixar de ter idealizações para o futuro do filho.

Estudar o tema proposto e entrevistar esses homens oportunizou refletir sobre a paternidade e a necessidade de fazer espaços para que eles possam trocar ideias e experiências. Especialmente, porque há grandes expectativas envolvidas nesta constituição do desejo de ser pai, além de múltiplas experiências.

Acredita-se assim, que ainda há muito que falar sobre o tema, para entender mais profundamente o processo de cada um, verificando a situação desses homens em diferentes momentos do ser pai. E, a partir do estudo realizado recomenda-se que haja futuras pesquisas que focalizem na construção desse desejo de paternidade, para maior compreensão do fenômeno e dos aspectos que a envolvem conforme as mudanças sociais.

\title{
PATERNITY: THE CONSTRUCTION OF PATERNAL DESIRE
}

\begin{abstract}
This research aimed to understand the development of the paternal wish, to verify how the relation between son and the one who is in the father role was constituted and it also aimed to identify the current perception men have about being a dad along with getting to know the aspects that directly influence the fatherhood exercise. A qualitative research was developed, in which three married man in heterosexual stable union, with 32, 36 and 49 years old, participated. The participants were chosen by a convenience criterion, being one of them not a
\end{abstract}


father yet, the other men will be, considering that he's wife is pregnant, and the third one already have a daughter. Along with that, the data collection was carried through a semi structure interview, developed individually with each men, in their own residence. The data were analyzed and interpreted considering the content analysis. From all this, it was understood that the relation between father and son has great influences in being a dad nowadays and that the perception that this men have about fatherhood is that it involves, mainly, the care, which is related to accompanying and directly participating in their child development. Therefore, it is realized that the realation wtih their child make this men rethink their father wish quote. That said, it is realized that all this process are important for the development of the paternal wish.

Keywords: Father Wish, Family, Fatherhood

\section{Referências}

BALANCHO, L. S. Ser pai hoje. A Paternidade em toda a sua Relevância e Grandeza. Curitiba: Juruá, 2012.

BARDIN, L. (2009). Análise de Conteúdo. Lisboa: Edições 70.

BENCZIK, E. B. P. A importância da figura paterna para o desenvolvimento infantil. Revista de Psicopedagia, v. 28, n. 85. São Paulo, 2011.

BYDLOWSKI, M. E LUCA, D. Depressão paterna e perinatalidade. In: Corrêa Filho, L., Corrêa Girade, M. H. \& França, P. (Orgs.). Novos olhares sobre a gestação e a criança até 3 anos: saúde perinatal, educação e desenvolvimento do bebê. Brasília: L.G.E. Editora, 2002.

DANTAS, C.; JABLONSKI, B. and FERES-CARNEIRO, T. Paternidade: considerações sobre a relação pais-filhos após a separação conjugal. Paidéia (Ribeirão Preto) [online]. 2004, vol.14, n.29, pp.347-357. ISSN 0103-863X. http://dx.doi.org/10.1590/S0103863X2004000300010. Acesso em: 07/10/2015.

FREITAS, W. M. F.; COELhO, E. A. C. ; SILVA, A. T. M. C. Sentir-se pai: a vivência masculina sob o olhar de gênero. Cad. Saúde Pública [online]. 2007, vol.23, n.1, pp. 137145. ISSN 1678-4464. Disponível em: http://dx.doi.org/10.1590/S0102311X2007000100015. Acesso em: 07/10/2015.

FREUD, Sigmund. A dissolução do Complexo de Édipo. Obras completas, ESB, v. XIX. Rio de Janeiro: Imago.

Janeiro: Imago.

Sobre o narcisismo, uma introdução. Obras completas, ESB, v. XIV. Rio de

GABRIEL, M. R. ; DIAS, A. C. G. Percepções sobre a paternidade: descrevendo a si mesmo e o próprio pai como pai. Estudos de psicolia (Natal) [online]. 2011, vol.16, n.3, pp. 253-261. ISSN 1413-294X. Disponível em: http://dx.doi.org/10.1590/S1413-294X2011000300007. Acesso em: 07/10/2015. 
HOUZEL, D. Os desafios da paternidade. Em L. Solis-Ponton, Um desafio para o terceiro milênio (pp. 27-31). México: Manual Moderno, 2004.

KROB, A. D.; PICCININI, C. A.; SILVA, M. R. A transição para a paternidade: da gestação ao segundo mês de vida do bebê. Psicol. USP [online]. 2009, vol.20, n.2, pp. 269-291. ISSN 0103-6564. Disponível em: http://dx.doi.org/10.1590/S0103-65642009000200008. Acesso em: 21/10/2015.

LACAN, J. As formações do inconsciente (1957-58). In: LACAN, J. O seminário. Tradução Dra. Vera Ribeiro. 1. Ed. Rio de Janeiro: Jorge Zahar Editor, 1999. (livro 5).

LAMY, Z. C.; ROCHA, L. J. L. F.; LIMA, J. R.; SILVA, E. L. C. Paternidade em tempos de mudança: Uma breve revisão da Literatura. Revista Pesquisa em Saúde, 13(2): 54-59, maioagosto, 2012.

MALDONADO, M. T.; DICKSTEIN, J. E.; NAHOUM, J. C. Nós estamos grávidos. São Paulo: Saraiva, 1997.

MARTINS, G. A. Estudo de caso: Uma estratégia de pesquisa. São Paulo: Atlas, 2006.

MARTINS, J.; BICUDO, M. A.V. A pesquisa qualitativa em psicologia. São Paulo: Morales, 1994.

NASIO, J. D. Édipo: o complexo do qual nenhuma criança escapa. Rio de Janeiro: Zahar, 2007.

NOGUEIRA-MARTINS, M. C. F.; BOGUS C. M. Considerações sobre a metodologia qualitativa como recurso para o estudo das ações de humanização em saúde. Saude soc. [online]. 2004, vol.13, n.3, pp. 44-57. ISSN 1984-0470. Disponível em: http://dx.doi.org/10.1590/S0104-12902004000300006.

PICCININI, C. A. et al. O envolvimento paterno durante a gestação. Psicologia, Reflexão e Crítica [online]. 2004, vol.17, n.3, pp. 303-314. ISSN 1678-7153. Disponível em: http://dx.doi.org/10.1590/S0102-79722004000300003. Acesso em: 28/10/2015.

RAMIRES, V. R. O exercício da paternidade. Rio de Janeiro: Rosa dos Tempos, 1997.

ROUDINESCO, E. ; PLON, M. Dicionário de Psicanálise. Rio de Janeiro: Jorge Zahar Editor, 1998.

SOUZA, B. M.; SANGUINET, E. T. Pais que assumiram sozinhos os cuidados parentais de seus filhos. Psicologia, Cachoeira do Sul. 2012.

VIOLANTE, M. L. V. Desejo de ter filhos ou desejo de maternidade ou paternidade. Jornal de Psicanálise, São Paulo, 40(72): 153-164 jun. 2007.

ZORNIG, S. M. A-J. Tornar-se pai, Tornar-se mãe: O processo de construção da parentalidade. Tempo psicanalítico, Rio de Janeiro, v. 42, n.2, p.453-470, 2010.

Data de recebimento: 19/05/2016 
Data de aceite: 06/07/2017

\section{Sobre as autoras:}

Cristiane Bottoli é Psicóloga, Mestre em psicologia, Docente do Curso de Psicologia do Centro Universitário Franciscano. Endreço Eletrônico: cbottoli@hotmail.com

Luana da Silva Gonçalves é Psicóloga formada pelo Centro Universitário Franciscano. Endreço Eletrônico: luana-sg@bol.com.br 